\title{
SEMIPERMEABLE ION-EXCHANGE MEMBRANES AS A PRECONCENTRATION MATRIX FOR TRACE ANALYSIS BY ELECTROCHEMICAL AND NEUTRON-ACTIVATION TECHNIQUES*
}

\author{
URI EISNer and HARRY B. Mark, JR. \\ Department of Chemistry, University of Michigan \\ Ann Arbor, Michigan, U.S.A.
}

(Received 26 April 1968. Accepted 4 July 1968)

\begin{abstract}
Summary-Ion-exchange membranes were used in conjunction with neutron-activation analysis and anodic stripping voltammetry for the determination of certain trace metal ions. The various parameters which govern the applicability, limitations and sensitivity of the methods were investigated. A new membrane "barrier" electrode assembly was introduced and found to be useful for the anodic stripping determination of trace metal ions in the presence of surface active materials.
\end{abstract}

THE application of the mercury-membrane electrode for voltammetry was introduced by Bowers and Wilson ${ }^{1}$ and was discussed in detail by Bowers and Murray. ${ }^{2}$ The membrane in this case was cellophane and acted as a fixed diffusion layer for the electroactive species to the electrode. These studies discussed in detail the diffusion model of the electrode process and its possible application to direct voltammetric analysis.

In a preliminary communication, ${ }^{3}$ a new electrode assembly for the anodic stripping technique was introduced in which the electrode material was pyrolytic graphite and a cellophane membrane acted as a diffusion laycr. The use of membranes was also extended to ion-exchange membranes. These membranes, recently introduced commercially, are produced as sheets which are homogeneous in composition with respect to the ion-exchange sites and their polymeric skeleton is polyethylene which is stable towards most acids, bases, and oxidants. The ion-exchange capacity of a particular membrane (Type $\mathrm{C}-103$ manufactured by the American Machine and Foundry Co., Springdale, Conn.) was similar to that of regular ion-exchange resins and was $1.3 \mathrm{meq} / \mathrm{g}$. (The usual application of these ion-exchange membranes is in electrodialysis, and a summary of the theoretical and experimental application of these membranes is given by Helfferich. ${ }^{4}$ )

Ion-exchange membrane electrodes have also been used in potentiometric precipitation $^{5}$ and acid-base ${ }^{6}$ titrations. A recent paper described the application of ionexchange membranes for enrichment of trace amounts of cations from large volumes of dilute electrolyte solution into a small volume of highly concentrated electrolyte solution. ${ }^{7}$ The membrane separated the two electrolyte solutions.

* This research was supported in part by a grant from the National Science Foundation; NSF GP 6425. Laboratory space and reactor time were donated by the Michigan Memorial Phoenix Project. 
The high affinity of the ion-exchange membranes for trace metal ions makes them suitable for use as a preconcentration matrix. After equilibration in the test solution they can be mounted in front of an electrode (as described in Ref. 3) for use in an anodic stripping technique. The membrane then acts as a reservoir of ions to be deposited on the electrode. This technique is most useful when direct anodic stripping is not possible because of inhibition of the electrochemical process by certain species such as surface active agents in the solution. The electrode itself can be either pyrolytic graphite or a mercury plated graphite electrode. Thus a wide range of potentials is covered which allows for the determination of most metal ions. Provided that the concentration of ions in the membrane is linearly related to their bulk concentration in the solution, the latter can be calculated. The pre-equilibrated membrane can also be analysed by neutron activation. This permits determination of species which are not suitable for electrochemical measurements and of species which are cspecially suited for trace analysis by ncutron activation. The two techniques have special conditions under which one is favoured over the other, as explained below.

The emphasis in this paper will be on the determination of the various parameters which govern the applicability of the ion-exchange membranes as a preconcentration matrix.

\section{Reagents and apparatus}

\section{EXPERIMENTAL}

All reagents were analytical grade and were used with no further purification. Demineralized water, which was then distilled twice (with potassium permanganate in the first stage of distillation) was used for preparing all stock solutions and for further dilutions.

Standard stock solutions of $0.1 M$ concentrations were made for each of the ions; silver, copper, cobalt and indium used in this study. Working solutions were prepared daily by dilution of the stock solutions.

The zinc tracer solutions were prepared by irradiating $2 \mathrm{mg}$ of zinc metal, encapsulated in quartz, for $24 \mathrm{hr}$ in the reactor. The irradiated metal was than dissolved in nitric acid and the solution diluted to $10 \mathrm{ml}$. The activity of the final solution $\left(3.28 \times 10^{-8} M\right.$ in zinc) was about $30000 \mathrm{cpm} / \mathrm{ml}$.

Before use, the ion-exchange membranes were washed in $1 M$ potassium hydroxide to remove oil and surface contaminants and then washed in $1 M$ nitric acid and twice-distilled water. The washed membranes were stored in water until use.

The construction and operation of the membrane "barrier" electrode assembly has been described previously. ${ }^{3}$

The electrodeposition and anodic stripping voltammetry were carried out with a three-electrode unit, constructed from the basic operational amplifier circuits of DeFord, ${ }^{8}$ and were recorded by a Mosley Autograph model 2D-2M X-Y recorder. The scan rates used throughout this work were $5-30 \mathrm{mV} / \mathrm{sec}$.

All irradiations were carried out in the Ford Nuclear Reactor of the Michigan Memorial Phoenix Project, which has a thermal neutron flux (in the pneumatic tubes) of $5 \times 10^{10} \mathrm{n} \cdot \mathrm{mm}^{-2} . \mathrm{sec}^{-1}$. The gamma counting and spectroscopy of the irradiated samples were accomplished with an RIDL 400channel analyser and a $75 \times 75 \mathrm{~mm} \mathrm{NaI(T1)} \mathrm{scintillation} \mathrm{crystal.}$

\section{Preconcentration of the metal ion in the membrane}

The cation-exchange membranes were equilibrated with the solution to be analysed, at a constant stirring rate. They were then removed and washed with water. The trace metal ion was determined either by neutron activation analysis or by anodic stripping voltammetry as described below.

Neutron-activation analysis. The equilibrated membranes were encapsulated in a polyethylene vial. The size of the membrane disc (diameter $10 \mathrm{~mm}$ ) matched the inside diameter of the vial, so that there was no free movement within it. The pneumatic polyethylene rabbit was also milled so that this vial fitted it without free movement. Thus, a constant geometry for irradiation was maintained through the experiments, the neutron flux in the membrane being kept as constant as possible.

After irradiation, the membrane was removed from the vial, enclosed in a new vial, and placed in the counting chamber. The process of removing and re-encapsulating took less than a minute, which permits the use of short-lived isotopes, with half-lives as short as $\mathbf{3 0} \mathrm{sec}$. 
Anodic stripping voltammetry. The membranes were pre-equilibrated and washed, as described above, for the anodic stripping voltammetry determinations. The membrane electrode was assembled and electrolysis carried out with a solution of the supporting electrolyte alone. As the only ions that are available for deposition on the electrode are those initially attached in the membranes as counterions, stirring has no effect on the deposition step and the electrolyses were thus carried out in a quiescent solution. The dissolution step in the analysis was carried out in the same solution after removal of the membrane.

\section{RESULTS AND DISCUSSION}

The ions $\mathrm{Ag}^{+}, \mathrm{Cu}^{2+}, \mathrm{Zn}^{2+}, \mathrm{Co}^{2+}$, and $\mathrm{In}^{3+}$ were used to demonstrate the methods described in this paper. As these ions can be detected easily by radioactivation analysis, the different parameters to be considered in the exchange processes were investigated by this method. The effect of variation of these parameters is described below.

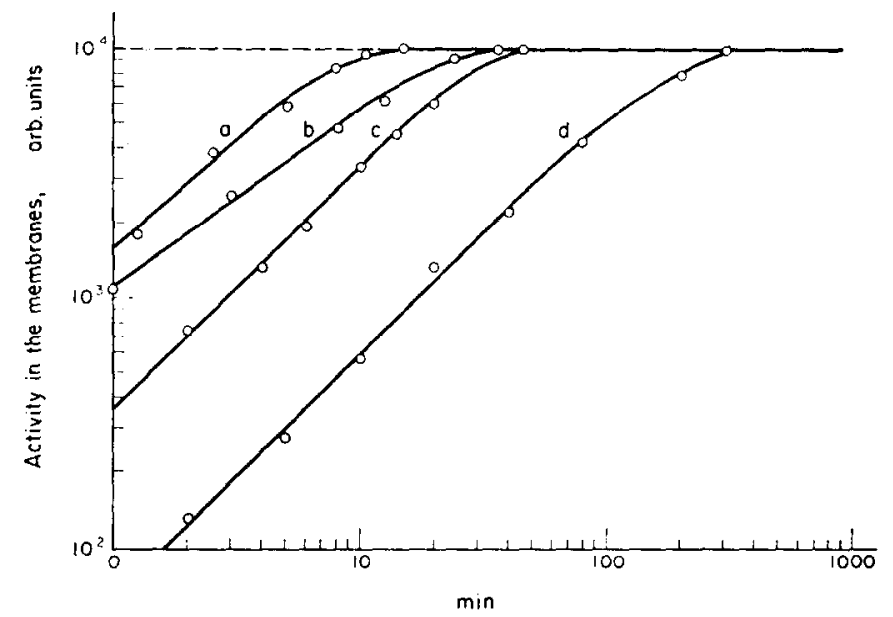

Fig. 1.-Equilibration time for membranes in various solutions.

(a) $3 \times 10^{-4} M \mathrm{Co}^{2+}, 0^{-1} M \mathrm{KNO}_{3} ;\left(\right.$ b) $2 \times 10^{-4} M \mathrm{Ag}^{+}, 0 \cdot 1 M \mathrm{KNO}_{8} ;(c) 2 \times 10^{-4} M$ $\mathrm{Cu}_{2}{ }^{+}, 0.1 M \mathrm{KNO}_{3} ;(d) 2 \times 10^{-5} M \mathrm{Zn}^{2+}, 0.01 M \mathrm{KNO}_{3}$.

\section{Equilibration time of the membrane}

The membranes were equilibrated in stirred solutions at $25^{\circ}$. As the concentration of the ion of interest is at trace level and the concentration of the counter-ion in the membrane is quite high ( $\sim 1 \mathrm{meq} / \mathrm{g}$ ), the exchange process can be described by the equations used for isotopic exchange governed by film diffusion. The rate of exchange is then proportional to the concentration of the trace ion diffusing to the membrane.4

The equilibration time for a trace metal concentration of $1 \times 10^{-4} M$ was found to be about $30 \mathrm{~min}$, for $2 \times 10^{-5} \mathrm{M}$ zinc it was $200 \mathrm{~min}$ (Fig. 1) and for $10^{-6} \mathrm{M}$ indium $24 \mathrm{hr}$. (The zinc equilibration studies were carried out with the long-lived (235-day) ${ }^{65} \mathrm{Zn}$ nuclide as tracer, and for the other metal ions neutron activation was used to determine their concentration in the membranes.) The equilibration times for the trace metal ions were found to be essentially independent of the concentration of the alkali metal ions in the supporting electrolytes.

Determination of the distribution factor, $\mathrm{D}_{\mathrm{i}}$, of the metal ion between solution and membrane

The degree of enrichment of the metal ion of interest in the membrane is related to the ion undergoing exchange. The exchange is a dynamic process and the 
enrichment proceeds until the ion in the membrane reaches a certain equilibrium concentration. A useful way to define the extent of enrichment is the distribution factor, $D_{\mathrm{i}}$ :

$$
D_{\mathrm{i}}=\frac{\mathrm{mg} \text { of metal in membrane } / \mathrm{g} \text { of membrane }}{\mathrm{mg} \text { of metal in solution } / \mathrm{g} \text { of solution }} .
$$

The $D_{1}$ values are determined by several chemical characteristics of the various ions such as oxidation state, charge density, and size. The experimental values of $D_{i}$ for the particular ions under investigation (in $0 \cdot 1 M$ potassium nitrate) are shown in Table I.

\begin{tabular}{cc}
$\begin{array}{c}\text { TABLE I.-Distribution } \\
\text { FACTOR VARIOUS IONS IN }\end{array}$ & $0 \cdot 1 M \mathrm{KNO}_{\mathbf{3}}$ \\
\hline FOn & \multicolumn{1}{c}{$\mathrm{D}_{\mathbf{1}}$} \\
\hline Ion & 30 \\
$\mathrm{Ag}^{+}$ & 240 \\
$\mathrm{Co}^{2+}$ & 250 \\
$\mathrm{Zn}^{2+}$ & 400 \\
$\mathrm{Cu}^{2+}$ & 13000 \\
$\mathrm{In}^{3+}$ & \\
\hline
\end{tabular}

It is essential that the volume of the equilibrated solution be sufficiently large for the ion concentration in solution to remain virtually constant during the course of the equilibration experiment.

In contrast to the equilibrium time, the $D_{1}$ values were found to vary with the concentration of the gross components (base electrolyte) in solution. In the case of ion-exchange resins, it is known that $D_{\mathrm{i}}$ is inversely proportional to the electrolyte concentration: $:^{10}$

$$
D_{\mathrm{i}}=\frac{\text { constant }}{A^{i / a}}
$$

where $A$ is the concentration of the electrolyte, $i$ is the ionic charge on the trace element and $a$ is the charge on the bulk ion.

A study was made to determine whether this relationship was valid for the ioncxchange membranes with potassium nitrate as the base electrolyte and $\mathrm{Ag}^{+}, \mathrm{Co}^{2+}$, $\mathrm{Cu}^{2+}$ and $\mathrm{In}^{3+}$ as the trace elements. While the plots of $\log D_{\mathrm{i}}$ vs. $\log A$ were linear as expected, the slopes were $-0.86,-1 \cdot 20,-1 \cdot 15$ and $-1 \cdot 25$ respectively (Fig. 2 ), considerably different from the predicted slopes ${ }^{10}$ of $-1 \cdot 0,-2 \cdot 0,-2 \cdot 0$ and $-3 \cdot 0$. The reason for this disagreement is not yet understood but it is possible that the conditions imposed in deriving equation (1) may not be met in this case.10

\section{Application of pre-equilibrated membranes as a preconcentration matrix for neutron-activation analysis}

Analytical calibration curves in $0 \cdot 1 M$ potassium nitrate were found to be linear over the concentration ranges $10^{-4}-10^{-5} M$ for $\mathrm{Cu}^{2+}$ and $\mathrm{Ag}^{+}, 10^{-6}-10^{-7} M$ for $\mathrm{In}^{3+}$ and $5-10 \times 10^{-5} \mathrm{M}$ for $\mathrm{Co}^{2+}$. The factors which determine the sensitivity attainable by this preconcentration step are $D_{i}$ and the usual parameters encountered in neutron activation. The parameters of importance for the ions $\mathrm{Ag}^{+}, \mathrm{Co}^{2+}, \mathrm{Cu}^{2+}$ and $\mathrm{In}^{3+}$ are summarized in Table II. 


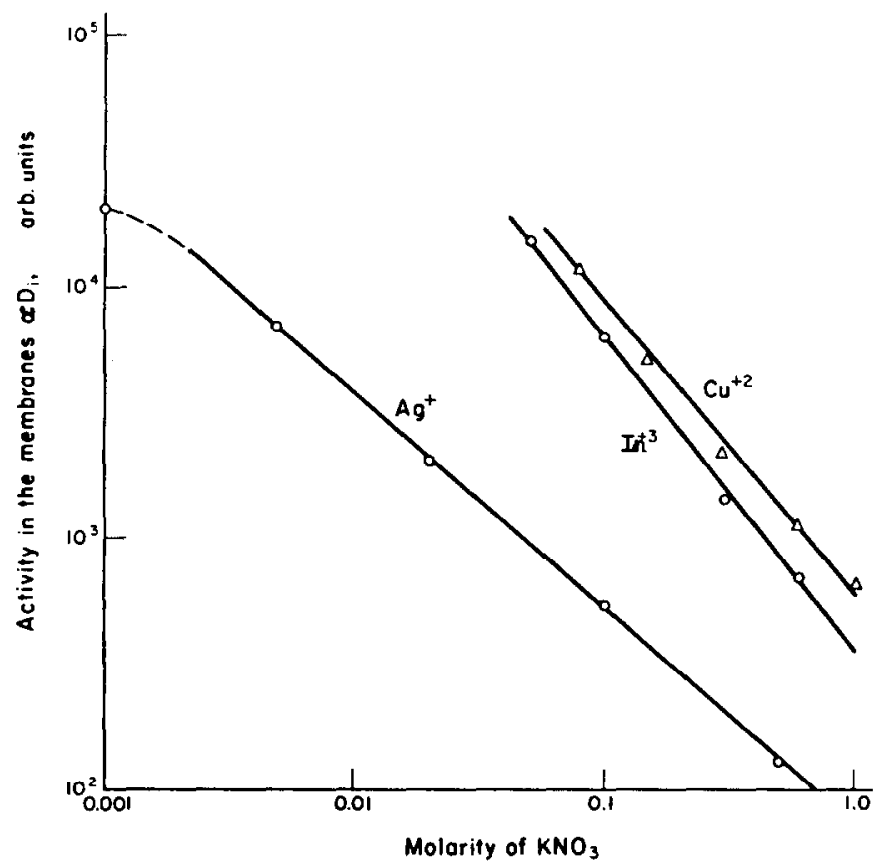

FIG. 2.-Dependence of the distribution factor of the trace ion on the concentration of supporting electrolyte.

TABLE II.-PARAMETERS AFFECTING SENSTTIVITY OF ION-EXCHANGE MEMBRANES AS A PRECONCENTRATION MATRIX FOR NEUTRON-ACTIVATION ANALYSIS

\begin{tabular}{lcccc}
\hline \multicolumn{1}{c}{ Parameter } & ${ }^{108} \mathrm{Ag}$ & ${ }^{60 m} \mathrm{Co}$ & ${ }^{66} \mathrm{Cu}$ & ${ }^{116 \mathrm{~m}} \mathrm{In}$ \\
\hline $\mathrm{D}_{1}$ & 30 & 240 & 400 & 13,000 \\
$\sigma$ (cross-section), barns & 35 & 18 & $2 \cdot 3$ & 154 \\
Abundance of parent, $\%$ & $51 \cdot 8$ & 100 & 30.9 & $95 \cdot 7$ \\
$t_{1 / 2}, \min$ & $2 \cdot 4$ & $10 \cdot 5$ & 5.1 & 54 \\
$\gamma$-Ray, $\mathrm{MeV}$ & 0.63 & $1 \cdot 33$ & 1.04 & $1 \cdot 27$ \\
Number of disintegrations per & $2 \cdot 0$ & 0.28 & 9 & 83 \\
\hline 100 atoms activated & & & & \\
\hline
\end{tabular}

These membranes can be used as a preconcentration matrix because they are essentially organic in nature and therefore do not themselves undergo any appreciable activation, as shown in Fig. 3, so the background from the matrix is very low.

For irradiation times of less than $5 \mathrm{~min}$ the lower limits of determination in $0.01 \mathrm{M}$ potassium nitrate are $\sim 1 \times 10^{-6} M \mathrm{Ag}^{+}, 5 \times 10^{-6} M \mathrm{Co}^{2+}, 5 \times 10^{-7} M \mathrm{Cu}^{2+}$ and $2 \times 10^{-10} M \mathrm{In}^{3+}$.

As several days are needed for equilibration of concentrations less than $10^{-6} M$, such dctcrminations under cquilibrium conditions are impractical.

However, as the rate of enrichment in the membrane is essentially linear with time up to approximately half the equilibrium concentration limit, the membranes could be left in contact with the sample solution for a fixed time interval, but considerable sensitivity would then be lost. 


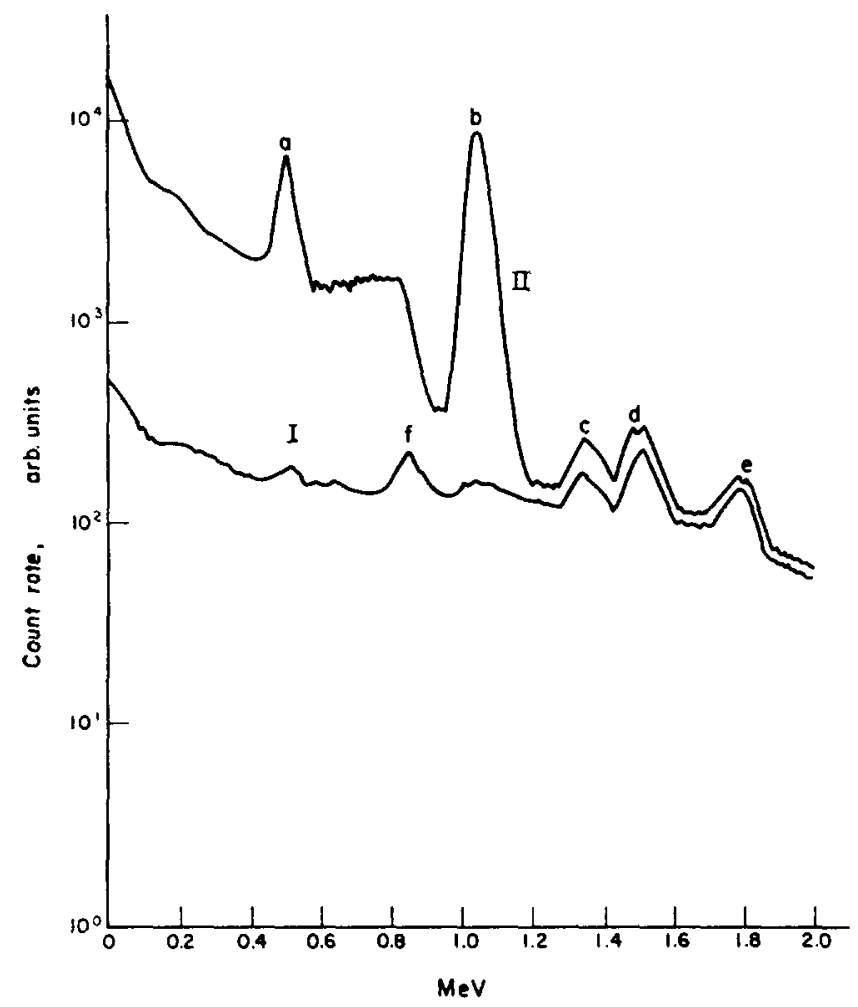

FIG. 3. - Gamma spectra of neutron-activated cation-exchange membranes.

I. Equilibrated in $0.1 M \mathrm{KNO}_{3}$; II. equilibrated in $0.1 M \mathrm{KNO}_{1}, 1 \times 10^{-8} M \mathrm{Cu}^{2+}$.

(a) ${ }^{64} \mathrm{Cu} 0.51-\mathrm{MeV}$ positron annihilation photopeak; (b) ${ }^{68} \mathrm{Cu} 1.04-\mathrm{MeV} ;(c){ }^{27} \mathrm{Na}$

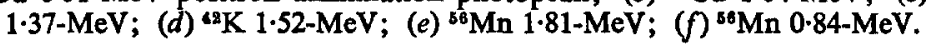

The determination of trace elements in the presence of surface active materials by anodic stripping voltammetry

In the analysis of biological materials in waste water the problem of surface active agents arises. These agents tend to adsorb on the electrode surface and, in many cases, suppress electrodeposition and the anodic dissolution peak. As already mentioned the use of membranes can circumvent this problem.

It was previously suggested that the ion-exchange membranes could act as a simple diffusion barrier with respect to the organic surface active agents while allowing the metal ions of interest to diffuse unhindered to the electrode..$^{3.9}$ It was found, however, that the times for the deposition step of anodic stripping were extremely long. This is a result of the complex mode of transport of the metal ions through a medium containing ion-exchange sites. The rate of transport of the ions through the membrane increases to a maximum as the loading reaches equilibrium. However, this maximum rate of transport is still considerably less (about half) than that observed without the membrane. Even with thin cellophane membranes (which have far fewer exchange sites) the deposition times were excessive. Thus it was decided to place the membranes in the stirred sample solutions before mounting in the electrode assembly. In this way equilibration was reached faster. The equilibrated membranes were then mounted in the electrode assembly for stripping analysis. 
A model system (silver ion in a supporting electrolyte of $0 \cdot 1 \mathrm{M}$ potassium nitrate and $1 M$ ammonia saturated with the surface active agent $\mathrm{n}$-octanol) was investigated. The n-octanol adsorbs strongly on the electrode in the potential range from -0.1 to $-0.9 \mathrm{~V}$ vs. S.C.E. ${ }^{11}$ so that the silver peak is suppressed and distorted when normal anodic stripping voltammetry techniques are used.

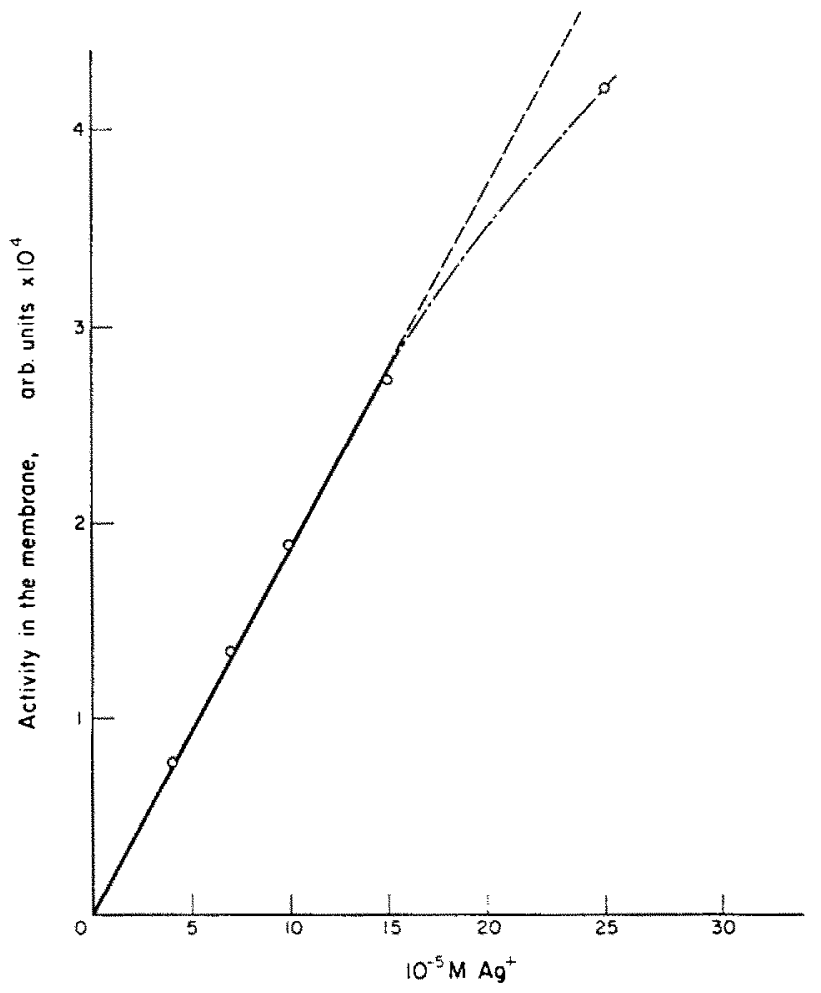

FIG. 4.-Calibration curve for silver in a solution saturated with n-octanol; supporting electrolyte $0.1 M \mathrm{KNO}_{3}$.

Membranes were equilibrated in the octanol solution and in another solution which contained the same concentrations of all species except the n-octanol. Activation analysis showed that both sets of membranes took up the same amount of silver. Thus, the octanol itself does not cause any appreciable disturbance in the ion-exchange process and the equilibration time.

A calibration curve for equilibrated membranes in silver solution in the presence of n-octanol was found to be linear in the range $4-15 \times 10^{-5} M$ (Fig. 4). Silver ion concentrations in this range were then determined by anodic stripping voltammetry with the membrane electrode assembly. An error of $\pm 5 \%$ was obtained. The procedure was as follows: three membranes were equilibrated in the solution and after equilibration were removed and washed with ethyl alcohol followed by water to remove any octanol adhering to the membrane. The membranes were then mounted in the electrode assembly and electrolysis was carried out in a solution of the base electrolyte alone $(0.1 M$ potassium nitrate, $0.5 M$ ammonia without octanol). The dissolution step was then carried out in the same solution after removal of the membrane. 
This method cannot be automatically applied for the analysis of any solution containing surface active materials, as it must be ascertained whether the surface active agent undergoes a reaction with the ion under consideration. This can be illustrated by the following experiment: a solution containing $5 \times 10^{-5} M \mathrm{Cu}^{2+}$ and $0.02 \%$ egg albumin showed no peak when a normal anodic stripping analysis was attempted. Equilibration of membranes in solutions containing various concentrations of copper ion showed a non-linear relationship between concentration of

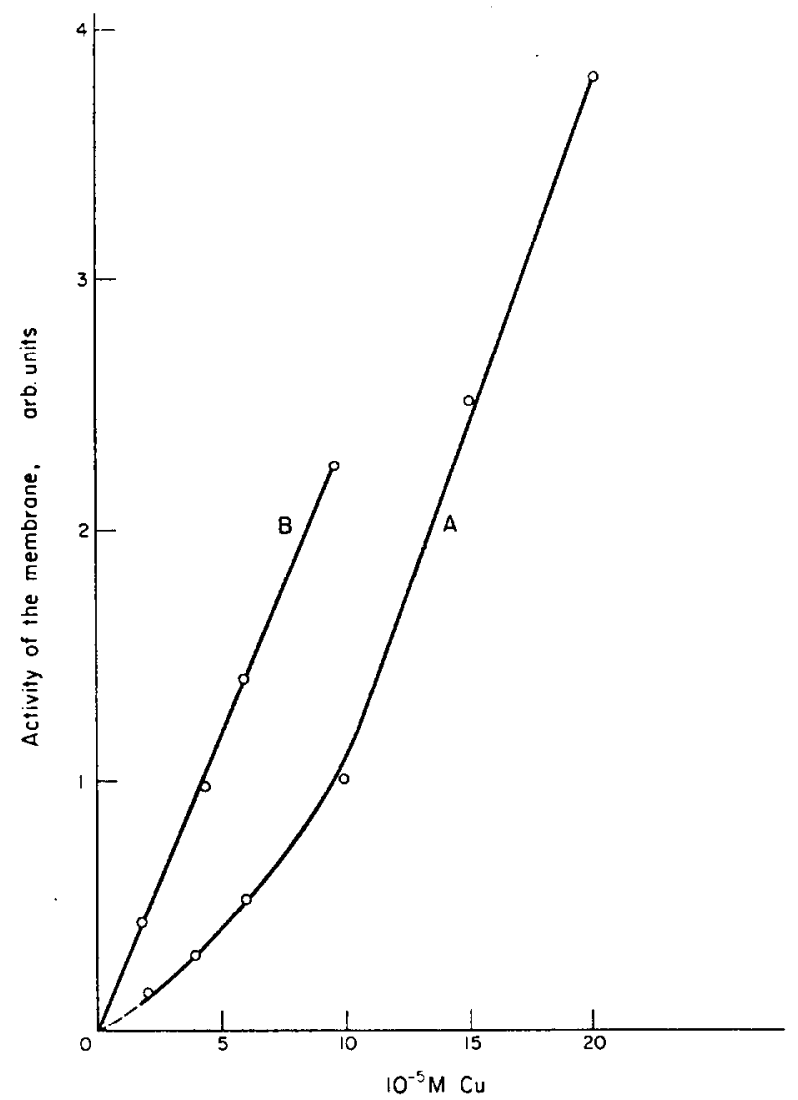

Fig. 5.-A. Calibration curve of copper in the presence of $0.02 \%$ alhumin, supporting electrolyte $0.1 M \mathrm{KNO}_{3}$ (a few drops of concentrated ammonia solution added to dissolve the albumin; for the two highest concentrations, the ammonia concentration was $0 \cdot 1 M$ ).

B. Calibration curve of copper in the presence of $0.02 \%$ albumin, supporting electrolyte $0 \cdot 1 M \mathrm{KNO}_{3}$ and $0 \cdot 1 M$ ethylenediamine.

copper in the membranes and its concentration in the solution (Fig. 5 curve A). This indicates that the copper undergoes reaction with the albumin to form a complex.

The complexation of copper ions by albumin has been discussed by Gurd and Wilcox. ${ }^{12}$ Kolthoff and Willeford ${ }^{13}$ found a stoichiometric reaction of copper with bovine serum albumin in an ammonia-ammonium nitrate buffer ( $\mathrm{pH} \mathrm{9.2).} \mathrm{On} \mathrm{the}$ other hand there was no reaction between copper and human serum albumin under the same conditions. 
In our case, the presence of $0 \cdot 1 \mathrm{M}$ ethylenediamine in the solution yielded a linear relationship between the concentration of copper in solution and its concentration in the membranes (curve B, Fig. 5). Equilibration of membranes in solutions containing $1 \times 10^{-4} M \mathrm{Cu}^{2+}, 0 \cdot 1 M$ potassium nitrate and $0.1 M$ ethylenediamine, showed the same uptake of copper in the presence and absence of egg albumin, indicating that the copper ions were complexed only with the ethylenediamine. When ammonia was used instead of ethylenediamine, it was found that even with $1 M$ ammonia the concentration of copper in the membranes was $25 \%$ lower than in the presence of $0.02 \%$ albumin. The large difference in the formation constants of the two complexing agents accounts for this $\left(\log K_{1}\right.$ for $\mathrm{Cu}-\mathrm{NH}_{3}$ is 4.27 and for $\mathrm{Cu}$-ethylenediamine $10 \cdot 72) .{ }^{14}$

\begin{abstract}
Zusammenfassung-Zur Bestimmung verschiedener Metallionen in Spurenmengen wurden Ionenaustauschmembranen in Verbindung mit Neutronenaktivierungsanalyse und anodischer stripping-Voltammetrie verwendet. Die verschiedenen Parameter wurden untersucht, die Anwendbarkeit, Grenzen und Empfindlichkeit der Methoden beeinflussen. Eine neue Membran-"Schranken"-Elektrode wurde eingeführt und zur Bestimmung von Metallionen in Spurenmengen durch "anodic stripping" in Gegenwart oberflächenaktiver Substanzen für nützlich befunden.
\end{abstract}

\begin{abstract}
Résumé-On a utilisé des membranes échangeuses d'ions en liaison avec l'analyse par activation de neutrons et la voltammétrie de dissolution anodique pour le dosage de certains ions métalliques à l'état de traces. On a étudié les divers paramètres qui régissent les possibilités d'application, les limitations et la sensibilité des méthodes. On a introduit un nouveau montage d'électrode a "barrière" membrane et l'a trouvé utile pour le dosage par dissolution anodique d'ions métalliques à l'état de traces en la présence de substances tensio-actives.
\end{abstract}

\title{
REFERENCES
}

1. R. C. Bowers and A. M. Wilson, J. Am. Chem. Soc., 1958, 80, 2968.

2. R. C. Bowers and R. W. Murray, Anal. Chem., 1966, 38, 461.

3. U. Eisner, J. M. Rottschafer, F. J. Berlandi and H. B. Mark, Jr., ibid., 1967, 39, 1466.

4. F. Helfferich, Ion Exchange, McGraw-Hill, New York, 1962.

5. F. P. Ijsseling and E. Van Dalen, Anal. Chim. Acta, 1966, 36, 166.

6. R. Geyer and P. Niklas, Z. Anal. Chem. 1960, 177, 166.

7. W. J. Blaedel and T. J. Haupert, Anal. Chem., 1966, 38, 1305.

8. D. D. Deford, Analytical Division, 133rd meeting ACS, San Francisco, California, 1958; B. H. Vassos, Ph.D. Thesis, University of Michigan, 1965.

9. F. J. Berlandi, Ph.D. Thesis, University of Michigan 1966.

10. O. Samuelson, Ion Exchange Separation in Analyrical Chemistry, Wiley, New York, 1963.

11. D. C. Graham, J. Am. Chem. Soc., 1946, 68, 301.

12. F. R. N. Gurd and P. E. Wilcox, Advan. Protein Chem., 1956, 11, 372.

13. I. M. Kolthoff and B. R. Willeford, Jr., J. Am. Chem. Soc., 1957, 79, 2656.

14. L. G. Sillén and A. E. Martell, Stability Constants of Metal-Ion Complexes, Spec. Publ. 17, Chemical Society, London, 1964. 